\title{
Effect of $\mathrm{CaO}$ Addition on Microstructure and Damping Capacity of AM50 Magnesium Alloy
}

\author{
Joong-Hwan Jun \\ Advanced Fusion Process R\&D Group, Korea Institute of Industrial Technology, Incheon 406-840, Korea
}

The effects of a small amount of $\mathrm{CaO}$ addition $(0.3$ mass $\%)$ on the microstructure and damping properties of AM50 casting alloys have been investigated. The added $\mathrm{CaO}$ contributes to the formation of an $\mathrm{Al}_{2} \mathrm{Ca}$ phase but reduces the total amount of compound particles by decreasing the $\beta$ phase content. The AM50-CaO alloy shows a slightly higher damping level within the strain-amplitude dependent region than does the alloy without $\mathrm{CaO}$. The lower number density of compound particles acting as strong pinning points for dislocations is thought to be responsible for the improvement in the damping capacity. [doi:10.2320/matertrans.M2012308]

(Received September 4, 2012; Accepted December 11, 2012; Published January 25, 2013)

Keywords: damping capacity, CaO, AM50, microstructure

\section{Introduction}

Because of the inherent advantages such as low density, high specific strength, good castability and damping properties, $\mathrm{Mg}$ alloys have recently gained increasing attention as a versatile material with distinct impact on the society. ${ }^{1,2)}$ Among the specific properties of $\mathrm{Mg}$ alloys, their low weight is an essential factor for consideration in designing transport vehicles and portable IT products: however, in view of safety, crashworthiness and comfort, the high damping characteristics of $\mathrm{Mg}$ alloys, which suppresses unwanted noise, irregular vibrations and resulting structural instabilities are also extremely important. ${ }^{3,4)}$ Recently, it has been reported that an addition of $\mathrm{CaO}$ into pure $\mathrm{Mg}$ or $\mathrm{Mg}-\mathrm{Al}$ based casting alloys enables the formation of dense films consisting of $\mathrm{CaO}$ and $\mathrm{MgO}$ on the molten surface without casting procedures involving $\mathrm{SF}_{6}{ }^{5,6)}$ Moreover, alloyed elemental $\mathrm{Ca}$ reduced from $\mathrm{CaO}$ results in improved mechanical properties at room and elevated temperatures by microstructural refinement and the introduction of $\mathrm{Ca}$-containing compounds with high thermal stability. ${ }^{7-9)}$ Despite several works on CaO-containing $\mathrm{Mg}$ alloys, ${ }^{5-9)}$ there is little information available on the damping capacity of commercial $\mathrm{Mg}-\mathrm{Al}$ based alloys with $\mathrm{CaO}$. Accordingly, in the present study, we comparatively examine the damping capacities of AM50 casting alloy with and without the addition of $\mathrm{CaO}$, and discuss the results on the basis of the microstructural evolution.

\section{Experimental}

Two AM50 based alloys having 0 and $0.3 \%$ (mass\%) $\mathrm{CaO}$, were prepared by remelting commercial billets supplied from the manufacturer and then casting them into a metallic mold. From the ingots, various specimens were prepared by machining for optical and electron microscopy, as well as for damping tests. The chemical compositions of the experimental alloys, as determined by an inductively coupled plasma (ICP), are listed in Table 1. The damping capacity was measured at room temperature using a dynamic mechanical analyzer (DMA, TA Q-800) in the strain

*Corresponding author, E-mail: jhjun@kitech.re.kr
Table 1 Chemical compositions of experimental alloys (mass\%).

\begin{tabular}{ccccc}
\hline Composition & $\mathrm{Al}$ & $\mathrm{Mn}$ & $\mathrm{Ca}$ & $\mathrm{Mg}$ \\
\hline AM50 & 5.09 & 0.31 & - & bal. \\
AM50-0.3\%CaO & 4.94 & 0.21 & 0.28 & bal. \\
\hline
\end{tabular}

amplitude range $1 \times 10^{-5}$ to $3 \times 10^{-3}$ vibrating in a single cantilever mode (frequency: $1 \mathrm{~Hz}$ ). The dimension of the damping test specimen was $35 \times 12 \times 1 \mathrm{~mm}^{3}$. The damping capacity was evaluated in terms of the loss tangent $(\tan \phi)$, where $\phi$ is the phase lag angle between the applied strain and the responding stress. Microstructural evaluations were carried out by optical microscopy (OM, Nikon Ephipot200BD), scanning electron microscopy (SEM, FEI QUANTA 200F) combined with energy dispersive X-ray spectroscopy (EDS, AMETEK PV72-60030F) and scanning transmission electron microscopy (STEM, JEOL JEM-ARM20F) with EDS (BRUKER QUANTAX 400).

\section{Results and Discussion}

\subsection{Microstructures}

Figure 1 shows the optical microstructures of AM50 and AM50-0.3\% CaO alloys in as-cast state. The microstructures consist of primary $\alpha-(\mathrm{Mg})$ grains and intermetallic particles distributed within the grains and along the grain boundaries. It is seen that the CaO-containing alloy has a slightly finergrained microstructure and a lower amount of intermetallic particles. The average grain size and the volume fraction of the intermetallic phase, measured by means of an image analysis, are $48 \mu \mathrm{m}$ and $\sim 16 \%$ in the AM50 and $40 \mu \mathrm{m}$ and $\sim 12 \%$ in the AM50-0.3\% CaO alloys, respectively. This microstructural evolution, owing to $\mathrm{CaO}$ addition, is closely related to the alloying of elemental $\mathrm{Ca}$ reduced from $\mathrm{CaO}^{7}$ ) and is very similar to that of $\mathrm{Mg}-\mathrm{Al}-\mathrm{Ca}$ alloys. ${ }^{10-12)}$ In a previous work, Amberger et al. ${ }^{10)}$ reported that an addition of $1 \% \mathrm{Ca}$ into $\mathrm{AZ91D}$ results in a decrease in the volume fraction of the $\beta\left(\mathrm{Mg}_{17} \mathrm{Al}_{12}\right)$ phase by the formation of $\mathrm{Al}_{2} \mathrm{Ca}$ (the total volume fraction of intermetallic particles may well be reduced because the $\mathrm{Al}_{2} \mathrm{Ca}$ phase needs a higher amount 


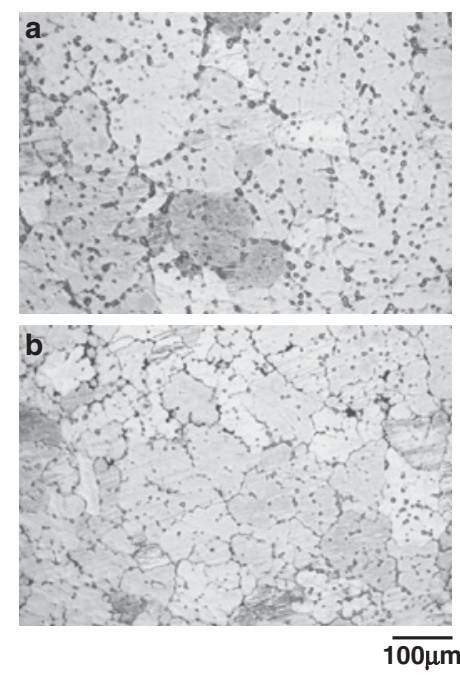

Fig. 1 Optical microstructures of (a) AM50 and (b) AM50-0.3\% CaO alloys in as-cast state.

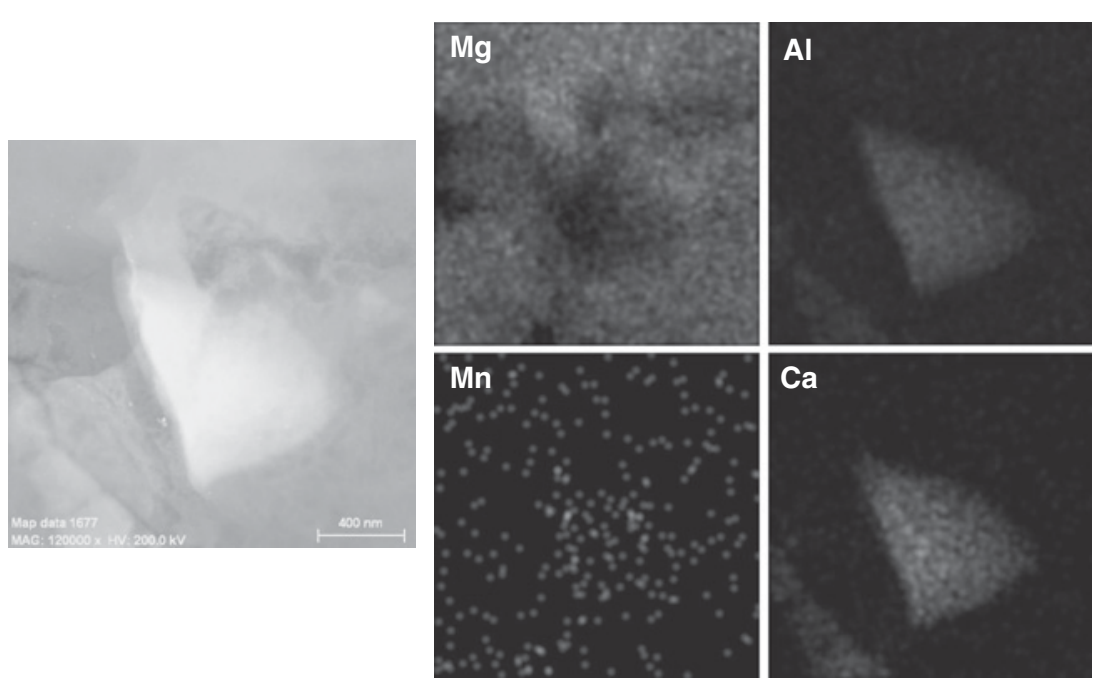

Fig. 2 TEM image showing an $\mathrm{Al}_{2} \mathrm{Ca}$ particle (left) and EDS maps of the elements $\mathrm{Mg}, \mathrm{Al}, \mathrm{Mn}$ and $\mathrm{Ca}$ (right) in $\mathrm{AM} 50-0.3 \% \mathrm{CaO}$ alloy.
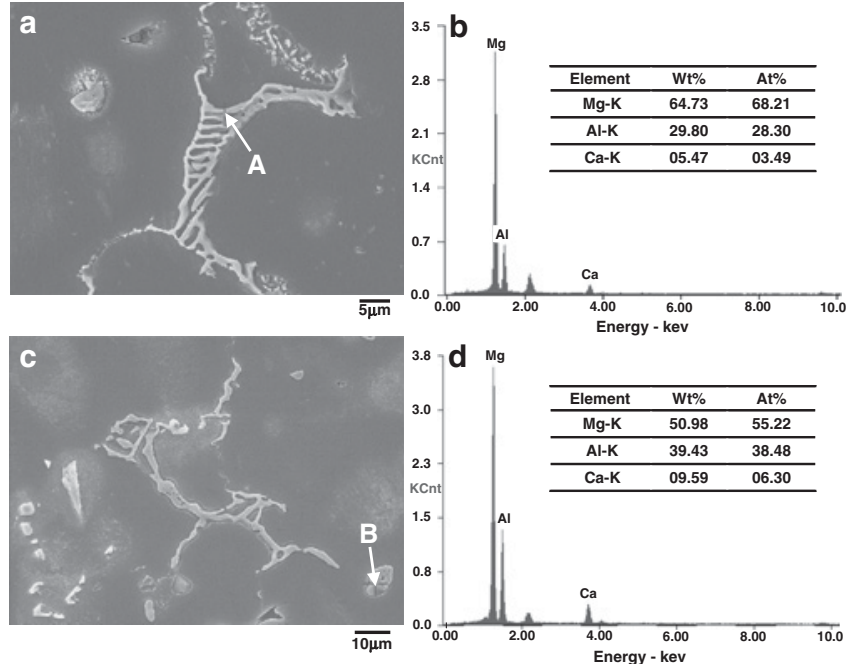

Fig. 3 (a) SEM image and (b) EDS analysis of the lamellar $\beta$ phase (A) and (c) SEM image and (d) EDS analysis of the bulky $\beta$ phase (B) in AM50 $0.3 \% \mathrm{CaO}$ alloy.

of alloying elements than does the $\beta$ phase, which consumes $\mathrm{Al}$ and $\mathrm{Mg}$ simultaneously).

A TEM image and the corresponding EDS mapping on an intermetallic particle of the AM50-0.3\% $\mathrm{CaO}$ alloy are presented in Fig. 2. Microanalysis performed on these particles indicates that the $\mathrm{Al}_{2} \mathrm{Ca}$ phase is formed in the matrix. Figure 3 shows SEM images and EDS compositional analyses on the $\beta\left(\mathrm{Mg}_{17} \mathrm{Al}_{12}\right)$ phase in the AM50 alloy with $0.3 \% \mathrm{CaO}$. It is noteworthy in Fig. 3 that lamellar and bulky types of the $\beta$ phase are seen in the microstructure and that $\mathrm{Ca}$ atoms dissolve in the $\beta$ phase. Inclusion of $\mathrm{Ca}$ in the $\beta$ phase was demonstrated theoretically by Min et al. ${ }^{13)}$ They calculated the valence electron structure (VES) of the $\beta$ phase by using empirical electron theory. Their results suggested that the addition of $\mathrm{Ca}$ results in a more uniform distribution of valence electrons in the dominant bonds and within the whole unit cell, causing an increase in the melting point of the $\beta$ phase. Recent results by Kondori et al. ${ }^{14)}$ confirmed that $\mathrm{Ca}$ atoms dissolve and distribute unevenly in the $\beta$ particles of the AM60-0.5\% Ca alloy.

\subsection{Damping capacity}

Figure 4 shows the change in damping capacity $(\tan \phi)$ with strain amplitude for the AM50 and AM50-0.3\% CaO alloys. As seen in Fig. 4, the damping curves can be divided into two regions. At low strains, the loss tangent is only weakly dependent on strain amplitude, whereas a distinct dependency on strain amplitude evolves at higher strains. It is noticeable that both the $\mathrm{CaO}$-containing and the $\mathrm{CaO}$ free alloys exhibit a similar damping capacity at low strain amplitudes, but slightly higher damping levels are observed for the $\mathrm{CaO}$-containing alloy at high strain amplitudes, even though the increment is not remarkable. This behavior is inconsistent with the results observed for $\mathrm{Mg}-\mathrm{Ca}$ binary alloys, where the damping capacity decreases continuously upon increasing Ca content. ${ }^{15)}$ After considering the previous reports that the addition of $\mathrm{Mn}$ up to $1 \%$ does not affect to the damping capacity in pure $\mathrm{Mg}^{16)}$ and rather slightly improves the damping capacity in $\mathrm{Mg}-\mathrm{Ni}$ alloys ${ }^{17)}$ the small difference in $\mathrm{Mn}$ content $(0.1 \%)$ in the experimental alloys is not likely to contribute to the damping capacity. This confirms that a better damping capacity is due to the microstructural evolution in response to $\mathrm{CaO}$ addition.

It is well known that the total damping capacity $(\delta)$ can be divided into two parts, namely, a strain-amplitude independent damping $\left(\delta_{\mathrm{O}}\right)$ and a strain-amplitude dependent damping $\left(\delta_{\mathrm{H}}\right) . \delta_{\mathrm{O}}$ is related to the loss caused by forced vibrations of dislocation segments pinned by weak pinning points such as solute atoms, while $\delta_{\mathrm{H}}$ results from the loss caused by dislocation segments pinned by strong pinning points such as precipitates and aggregates. According to the Granato and Lücke (G-L) theory, ${ }^{18,19)} \delta$ can be described as follows:

$$
\begin{aligned}
\delta & =\delta_{\mathrm{o}}+\delta_{\mathrm{H}}(\varepsilon) \\
\delta_{\mathrm{o}} & \sim \rho L_{\mathrm{d}}^{4} \\
\delta_{\mathrm{H}}(\varepsilon) & =\frac{C_{1}}{\varepsilon} \exp \left(\frac{-C_{2}}{\varepsilon}\right)
\end{aligned}
$$




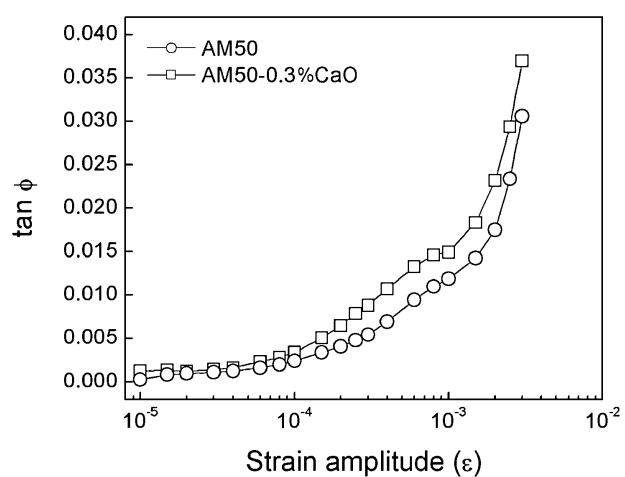

Fig. 4 Change in $\tan \phi$ with strain amplitude in AM50 and AM50$0.3 \% \mathrm{CaO}$ alloys.

$$
\begin{aligned}
C_{1} & =\frac{\rho F_{\mathrm{B}} L_{\mathrm{N}}^{3}}{6 b E L_{\mathrm{d}}} \\
C_{2} & =\frac{K b \eta}{L_{\mathrm{d}}}
\end{aligned}
$$

where $\rho$ and $L_{\mathrm{d}}$ are the dislocation density and the average distance between weak pinning points, $F_{\mathrm{B}}, E, L_{\mathrm{N}}, b, K$ and $\eta$ are the binding force between dislocations and weak pinning points, the elastic modulus, the average distance between strong pinning points, the Burgers vector, a constant and the size ratio of solvent and solute atoms, respectively. On the basis of the G-L theory, a slightly higher damping level in the strain-amplitude dependent region $\left(\delta_{\mathrm{H}}\right)$ of the $\mathrm{CaO}$-containing alloy, as shown in Fig. 4, can be explained by a smaller amount of intermetallic particles acting as strong pinning points. When the number density of precipitates acting as strong pinning points is reduced, $\delta_{\mathrm{H}}$ in eq. (3) increases, since the lower number density of intermetallic particles can yield a higher $C_{1}$ term by increasing the $L_{\mathrm{N}}$ value. In a previous work, ${ }^{20)}$ we demonstrated that $\mathrm{Ca}$ solutes in the $\mathrm{CaO}$-added alloy do not exist in the matrix owing to the low solubility of $\mathrm{Ca}$ in $\mathrm{Mg}$. This implies that there is no substantial difference in the matrices for both alloys, thus the $C_{2}$ values are likely the same in response to the same $L_{\mathrm{d}}$ values. An enhanced damping level due to a decreasing number density of intermetallic particles was also reported by Zhang et al. for the AZ91D alloy. ${ }^{21)}$ They found that the solution-treated AZ91D alloy without $\beta$ particles has a higher damping capacity than the as-cast and aged samples having $\beta$ compound particles distributed in the microstructure. This result suggests that the $L_{\mathrm{N}}$ values of as-cast and aged specimens become lower owing to a bigger quantity of the $\beta$ phase, in turn leading to a lower value of $C_{1}$. In order to obtain the $C_{1}$ and $C_{2}$ values of the AM50 and AM50$0.3 \% \mathrm{CaO}$ alloys, $\ln \left(\delta_{\mathrm{H}} \times \varepsilon\right)$ within the strong strain-amplitude dependent region is plotted against $1 / \varepsilon$ in Fig. 5 using the relation $\delta=\pi \tan \phi(\tan \phi<0.06)$ relation. $\left.{ }^{21}\right)$ In this figure, $\ln \left(C_{1}\right)$ and $C_{2}$ correspond to the $Y$-axis intercept and the slope, respectively. The obtained $C_{1}$ and $C_{2}$ values are $8.8 \times 10^{-4}$ and $3.96 \times 10^{-3}$ for the AM50 and $12.1 \times 10^{-4}$ and $4.05 \times 10^{-3}$ for the AM50-0.3\% CaO alloys. The CaOadded alloy has a higher value of $C_{1}$, but an almost identical value of $C_{2}$, which supports well the experimentally observed enhanced damping capacity by $\mathrm{CaO}$ addition at high strain amplitudes.

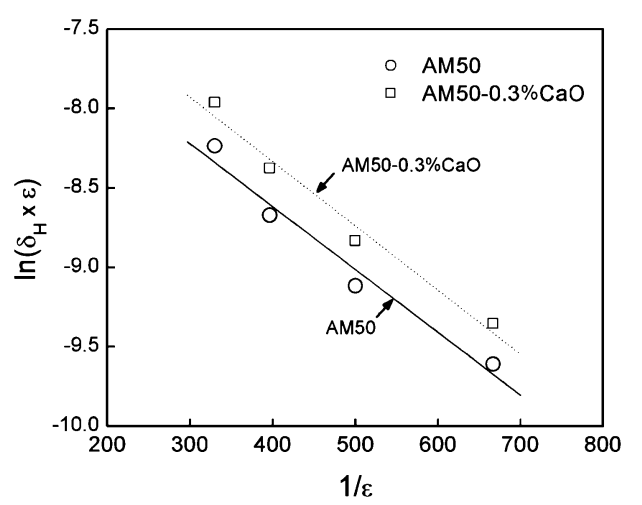

Fig. 5 G-L plots of AM50 and AM50-0.3\% CaO alloys.

\section{Conclusion}

The microstructures and damping properties of AM50 alloys with and without addition of $\mathrm{CaO}$ were comparatively investigated. The small amount $(\sim 0.3 \mathrm{mass} \%)$ of additional $\mathrm{CaO}$ causes the formation of the $\mathrm{Al}_{2} \mathrm{Ca}$ phase in the microstructure: however, the addition reduces the total amount of compound particles by decreasing the $\beta$ phase content. The $\mathrm{CaO}$ addition leads to a better damping capacity at high strain amplitudes. The reason could be related to the lower number density of compound particles acting as strong pinning points for dislocations.

\section{REFERENCES}

1) B. L. Mordike and T. Ebert: Mater. Sci. Eng. A 302 (2001) 37-45.

2) H. Friedrich and S. Schumann: J. Mater. Proc. Tech. 117 (2001) 276281.

3) K. Sugimoto, K. Matsui, T. Okamoto and K. Kishitake: Trans. JIM 16 (1975) 647-656.

4) K. Sugimoto, K. Niiya, T. Okamoto and K. Kishitake: Trans. JIM 18 (1977) 277-288.

5) S. H. Ha, J. K. Lee and S. K. Kim: Mater. Trans. 49 (2008) 1081-1083.

6) J. K. Lee and S. K. Kim: Mater. Trans. 52 (2011) 1483-1488.

7) J. H. Seo and S. K. Kim: Mater. Sci. Forum 620-622 (2009) 291294.

8) H. K. Kim, S. K. Kim and D. H. Kim: J. Kor. Found. Soc. 32 (2012) 44-49.

9) E. H. Cho, J. H. Jun and Y. J. Kim: Kor. J. Mater. Res. 22 (2012) 499-503.

10) D. Amberger, P. Eisenlohr and M. Göken: Mater. Sci. Eng. A 510-511 (2009) 398-402.

11) Q. Wang, W. Chen, X. Zeng, Y. Lu, W. Ding, Y. Zhu and X. Xu: J. Mater. Sci. 36 (2001) 3035-3040.

12) P. Li, B. Tang and E. G. Kandalova: Mater. Lett. 59 (2005) 671-675.

13) X. G. Min, Y. S. Sun, F. Xue, W. W. Du and D. Y. Wu: Mater. Chem. Phys. 78 (2003) 88-93.

14) B. Kondori and R. Mahmudi: Mater. Sci. Eng. A 527 (2010) 2014 2021.

15) D. Wan, J. Wang, L. Lin, Z. Feng and G. Yang: Physica B 403 (2008) 2438-2442.

16) S. Chen, X. Dong, R. Ma, L. Zhang, H. Wang and Z. Fsn: Mater. Sci. Eng. A 551 (2012) 87-94.

17) W. Diqing, W. Jincheng, W. Gaifang, C. Xianyi, L. Lin, F. Zhigang and Y. Gencang: Mater. Sci. Eng. A 494 (2008) 139-142.

18) A. Granato and K. Lücke: J. Appl. Phys. 27 (1956) 583-593.

19) A. Granato and K. Lücke: J. Appl. Phys. 27 (1956) 789-805

20) J. H. Jun: Collected Abstracts of the 2011 Spring Meeting of the Korean Society for Heat Treatment, (2011) pp. 191-192.

21) Z. Zhang, X. Zeng and W. Ding: Mater. Sci. Eng. A 392 (2005) 150155. 